$$
\text { Conf-94106/.-18 }
$$

\title{
UCRL-JC-117142
}

PREPRINT

\section{Characterization Inconsistencies in CdTe and CZT Gamma-Ray Detectors}

\author{
Anthony D. Lavietes \\ James H. McQuaid
}

This paper was prepared for submittal to the

1994 IEEE Nuclear Science Symposium and Medical Imaging Conference, Norfolk, Virginia, October 30 - November 5, 1994

October 1994

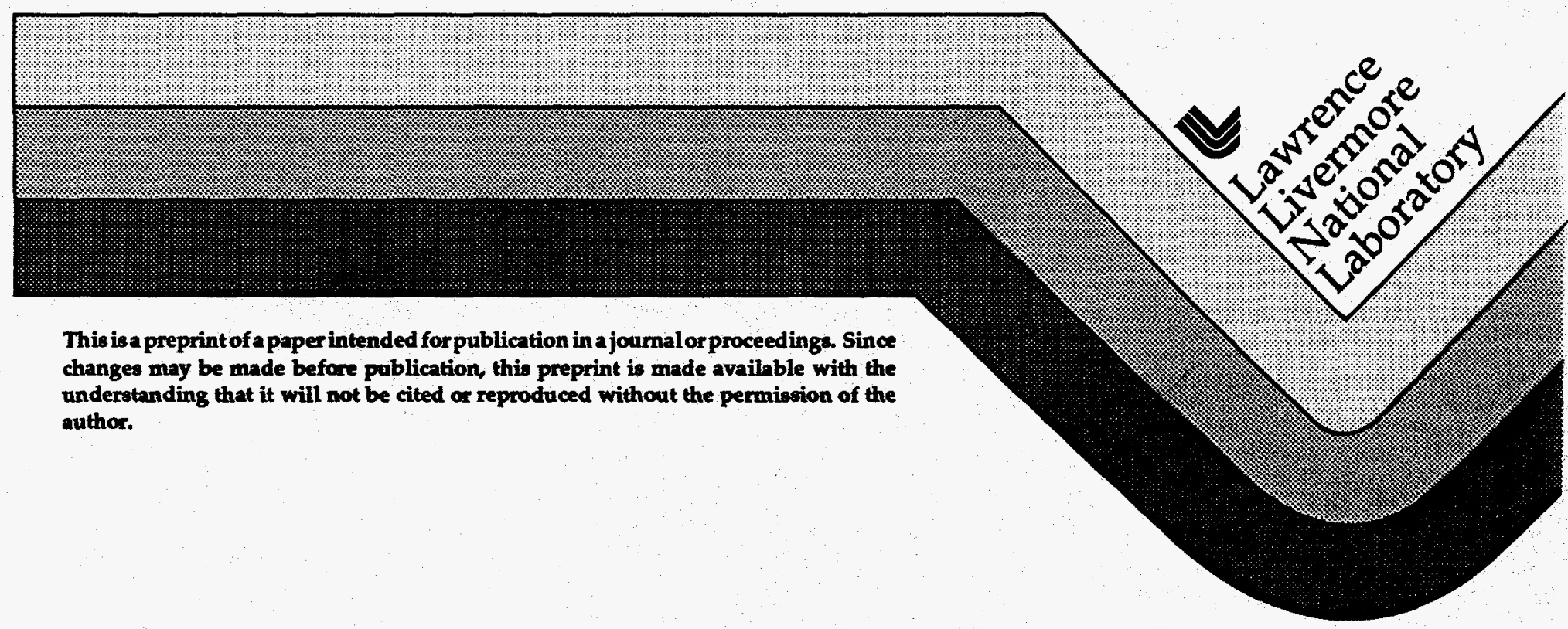


DISCLAIMER

This document was prepared as an account of work sponsored by an agency of the United States Government. Neither the United States Government nor the University of California nor any of their employees, makes any warranty, express or implied, or assumes any legal liability or responsibility for the accuracy, completeness, or usefulness of any information, apparatus, product, or process disclosed, or represents that its use would not infringe privately owned rights. Reference herein to any specific commercial products, process, or service by trade name, trademark, manufacturer, or otherwise, does not necessarily constitute or imply its endorsement, recommendation, or favoring by the United States Government or the University of California. The views and opinions of authors expressed herein do not necessarily state or reflect those of the United States Government or the University of California, and shall not be used for advertising or product endorsement purposes. 


\section{DISCLAIMER}

Portions of this document may be illegible in electronic image products. Images are produced from the best available original document. 


\title{
Characterization Inconsistencies in CdTe and CZT Gamma-Ray Detectors ${ }^{1}$
}

\author{
A.D. Lavietes, J. H. McQuaid \\ Lawrence Livermore National Laboratory
}

\begin{abstract}
In the past few years, significant developments in cadmium telluride (CdTe) and cadmium zinc telluride (CZT) semiconductor materials have taken place with respect to both quality and yield. Many of the more recent developments have occurred in the area of CZT crystal growth. This has resulted in an explosion of interest in the use of these materials in ambient temperature gamma-ray detectors. Most, if not all, of the manufacturers of CdTe and CZT have acquired government funding to continue research in development and applications, indicating the importance of these improvements in material quality.

We have examined many detectors, along with the accompanying manufacturer's data, and it has become apparent that a clear standard does not exist by which each manufacturer characterizes the performance of their material. The result has been a wide variety of performance claims that have no basis for comparison and normally cannot be readily reproduced.

In this paper we will first- support our observations and then propose a standard that all manufacturers and users of these materials may use for characterization.
\end{abstract}

\section{INTRODUCTION}

CdTe and CZT semiconductor materials have been used in radiation detection instrumentation for many years[1,2,3,4]. Experimentation with these materials indicated that there were a number of methods being used to determine performance by manufacturers. This was mainly due to a significant low energy tailing phenomenon associated with the slow charge collection characteristics of these materials. Example spectra are shown in Figures 1 and 2. Both of these spectra have the same FWHM, but have significantly different tailing profiles.

Most manufacturers were not sure how to consider this tailing problem, some choosing to ignore it completely. Differing characterization methods led to arbitrary performance data that was not verifiable without prior knowledge of the method that was used. To obtain a complete description of the detector performance, it is necessary that both the FWHM and tailing information be reported. Without considering the tailing as an integral part of the detector characterization, the performance could be misrepresented.

${ }^{1}$ This work was performed under the auspices of the U.S. Department of Energy (DOE) by the Lawrence Livermore National Laboratory under contract No. W-7805-Eng-48

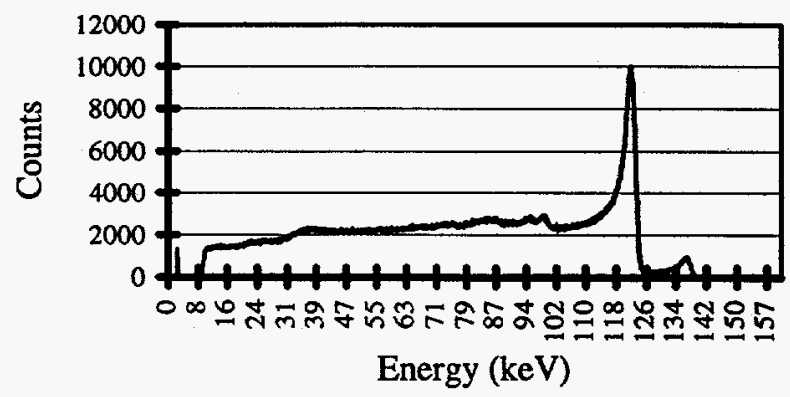

Fig. $12 \times 2 \times 2 \mathrm{~mm}$ CdTe Detector

\section{CURRENT METHODS OF CHARACTERIZATION}

There are currently three methods known that manufacturers use to characterize their material; software analysis, high-side FWHM $\times 2$, and absolute FWHM from the baseline.

\section{A. Software Analysis}

The software analysis packages that are commercially available are designed to take advantage of the well behaved, almost perfectly Gaussian pulse shapes obtained from a germanium detector system. In fact, most analytical software is designed specifically for the detailed analysis of germanium spectra. The algorithms implementedin these analysis tools do not model the tailing effects characteristic of CdTe or CZT detectors. The result is rather optimistic resolution and performance data.

\section{B. High-Side FWHM $\times 2$}

A second method presents the FWHM data as though the spectral line presented itself as perfectly Gaussian. The centroid of the spectral line is determined and then subtracted

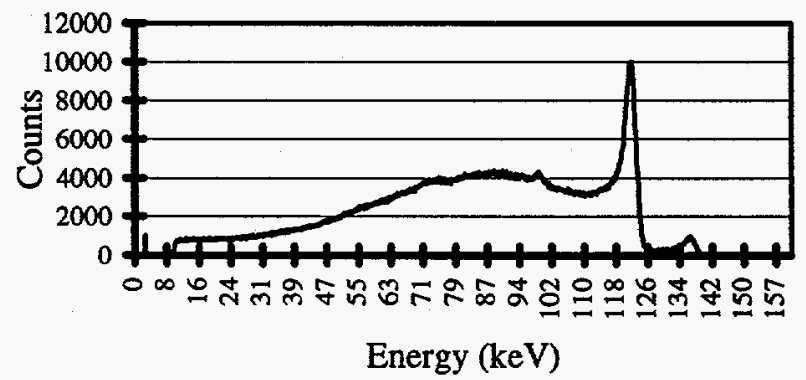

Fig. $22 \times 2 \times 2 \mathrm{~mm}$ CZT detector

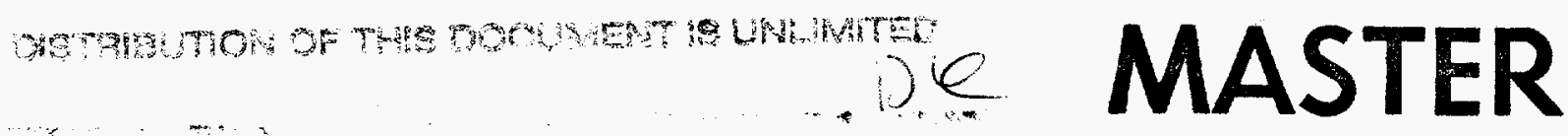


from the absolute half-maximum point on the high energy side of the spectral line. This result is then multiplied by two and reported as the FWHM of that particular energy line. Obviously this method ignores all charge collection and trapping problems that result in spectral broadening and, again, gives optimistic resolution and performance data.

\section{Absolute FWHM From Baseline}

The third method simply takes the FWHM measurement across the spectral line of interest at the absolute halfmaximum point of the peak. This method is the most accurate and descriptive, in that it takes into account all phenomenon that result in spectral broadening. The only information that is missing from this characterization technique is a tail profile. A comparison for the CZT $2 \times 2 \times 2$ $\mathrm{mm}$ detector using each method is shown in Table 1.

\section{PROPOSED CHARACTERIZATION METHOD}

We have proposed a method that characterizes CdTe and CZT detectors in a way that is both reproducible and descriptive, such as the procedures in the IEEE Standard For Germanium Detectors (ANSI/IEEE Std 325-1986). We determined that a method similar to the IEEE Standard For Semiconductor X-Ray Energy Spectrometers (ANSI/IEEE Std 759-1984) could be used. This standard incorporates procedures for characterizing tailing phenomenon and could be modified to address the features found in CdTe and CZT detectors.

Using existing standards as a model would serve to accelerate the consideration and acceptance of the proposed standard by industry. Many domestic manufacturers and several individuals involved in IEEE standard development have been consulted. They have either implemented this proposed method (or a subset of the method) or have acknowledged the need and have expressed their support for a new standard.

\section{A. Method}

The absolute FWHM method for resolution was adopted since it is the most representative and also already implemented in all other characterization methods.

The emphasis in this work was to determine a descriptive method to profile the tailing associated with CdTe and CZT detectors. The X-ray standard mentioned above contains a method for profiling the tailing of silicon detectors by calculating tailing ratios at three positions in the tail relative to the peak. By applying this same process, the tailing of CdTe and CZT detectors could also be described.

Reproducible tailing informationcan be obtained using

\footnotetext{
${ }^{2}$ Monte Carlo N-Particle Transport Code System (MCNP 4A), Los Alamos National Laboratory, Los Alamos, New Mexico.
}

Table 1

Comparison of Characterization Methods

\begin{tabular}{|c|c|}
\hline Characterization Method & FWHM (keV) \\
\hline Software Analysis & 3.27 \\
\hline High-side FWHM x 2 & 2.7 \\
\hline Absolute FWHM & 3.98 \\
\hline
\end{tabular}

${ }^{57} \mathrm{Co}$, therefore we recommended the implementation of the $122 \mathrm{keV}$ line of ${ }^{57} \mathrm{Co}$ in this method. An $\mathrm{MCNP}^{2}$ Monte Carlo simulation was performed as part of the process used to determine this energy. The simulation provided information to help determine positions in the tail that would be free from interference. The detector model used was a $10 \mathrm{~mm}$ diameter $x 3 \mathrm{~mm}$ thick CZT detector with no enclosure. Furthermore, the spectrum was optimized relative to peak shape in order to study the escape peaks. The resulting spectrum is shown in Figure 3.

The X-ray escape peaks for cadmium, zinc, and tellurium are clearly visible below the $122 \mathrm{keV}$ peak. It is important to ensure that the method that was developed not be limited by future improvements in material technology. For this reason, the energies of $120 \mathrm{keV}, 116 \mathrm{keV}$, and $102 \mathrm{keV}$ were chosen. If the resolution and performance of these detectors improve in the future to the point where the X-ray escape peaks can be resolved, they will not interfere in the characterization.

The recommended method for reporting resolution is as follows:

- Use the $122 \mathrm{keV}$ peak of ${ }^{57} \mathrm{Co}$ in all measurements.

- Determine the absolute FWHM of the peak.

- Determine the tailing profile by reporting the peak-to-tail ratios for the three energies as follows:

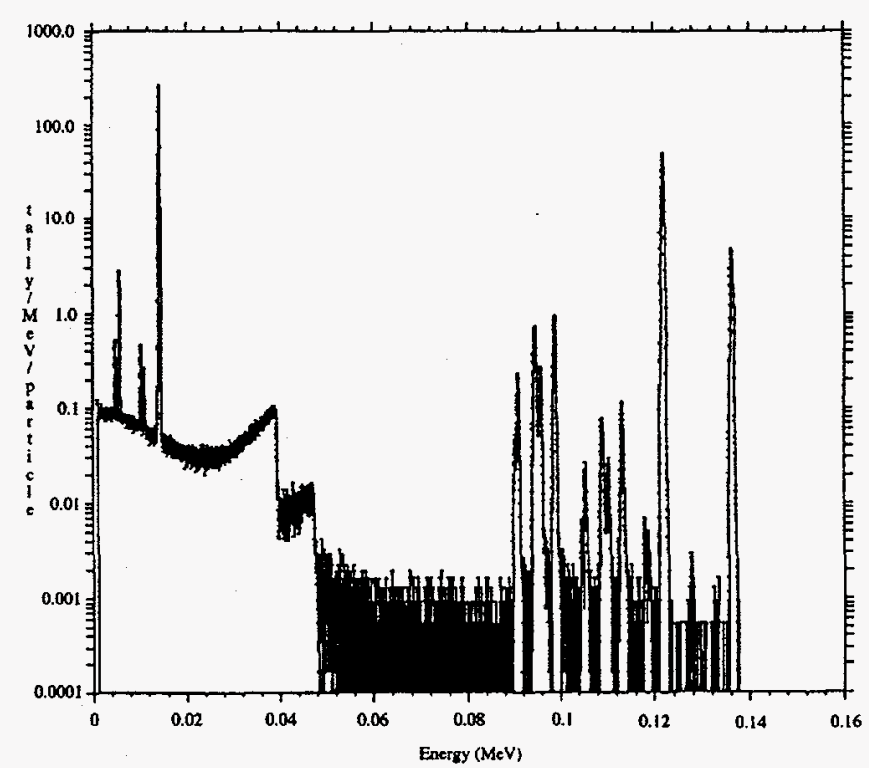

Fig. 1 Optimized MCNP Monte Carlo Spectrum for CZT 


$$
\begin{aligned}
& \mathrm{TP}_{1}=\frac{\text { Peak Amplitue }(122 \mathrm{keV})}{\text { Tail Amplitude }(120 \mathrm{keV})} \\
& \mathrm{TP}_{2}=\frac{\text { Peak Amplitude }(122 \mathrm{keV})}{\text { Tail Amplitude }(116 \mathrm{keV})} \\
& \mathrm{TP}_{3}=\frac{\text { Peak Amplitude }(122 \mathrm{keV})}{\text { Tail Amplitude }(102 \mathrm{keV})}
\end{aligned}
$$

Where:

$\operatorname{TP}_{\mathrm{x}}=$ Tailing Profile for each tail energy position.

\section{CONCLUSIONS}

Applying this method for the characterization of CdTe and CZT detectors result in reliable, reproducible, and accurate resolution and performance data. This method has the benefit of being based on proven IEEE standards and shows that it is flexible enough to accommodate technological advances without significant modifications. Several manufacturers and members of the IEEE Standards Committee have expressed their support.

\section{REFERENCES}

[1] J.F. Butler, F.P. Doty, C. Lingren, and B. Apotovsky, "Cadmium Zinc Telluride Detectors for Industrial Radiation Measurement," 2nd Topical Meeting on Industrial Radiation and Radioisotope Measurement Applications, Raleigh, September 8-11, 1992.

[2] G. Entine, P Waer, T. Tiernan, and M.R. Squillante, "Survey of CdTe Nuclear Detector Applications," Nuclear Instruments and Methods in Physics Research, vol. A283, pp. 282-290, May 1989.

[3] R. Arlt, K.H. Czock, and D.E Rundquist, "Overview of the Use of CdTe Detectors for the Verification of Nuclear Material in Nuclear Safeguards," Nuclear Instruments and Methods in Physics Research, vol. A322, no. 3, pp. 575-582, November, 1992.

[4] E. Raiskin and J. F. Butler, "CdTe Low Level Gamma Detectors Based on a New Crystal Growth Method," IEEE Transactions on Nuclear Science, vol. 35 no. 1, pp. 81-84, February 1988. 